\title{
Leucopenia during sulphasalazine treatment for rheumatoid arthritis
}

\author{
M MARABANI, ${ }^{1}$ R MADHOK, ${ }^{1}$ H A CAPELL, ${ }^{1}$ AND J A HUNTER \\ From the ${ }^{1}$ Centre for Rheumatic Diseases, Glasgow Royal Infirmary, Glasgow and ${ }^{2}$ Gartnavel General \\ Hospital, Glasgow
}

SUMMARY Leucopenia appears to be a more frequent complication of sulphasalazine treatment in rheumatoid arthritis than in inflammatory bowel disease and poses a management problem. In this study leucopenia was found in 20 patients, 14 of whom were participating in prospective studies (252 patients), giving an incidence of $5.6 \%$. Treatment had to be discontinued in half of these patients. Most (14) episodes of leucopenia occurred early in treatment ( $<24$ weeks) but some occurred late and sustained monitoring seems necessary. No predictive factors for leucopenia were elucidated. All patients recovered fully with dose adjustment or, in more severe cases, after withdrawal of sulphasalazine and appropriate supportive therapy. The incidence of leucopenia may be higher in Glasgow than in other units in Britain.

Sulphasalazine is an effective second line drug in rheumatoid arthritis. Life threatening leucopenia has, however, been reported in patients receiving sulphasalazine for inflammatory bowel disease and in patients with rheumatoid arthritis. ${ }^{1}$ The incidence and outcome of leucopenia during sulphasalazine treatment for rheumatoid arthritis are not known. Initial experience suggests that leucopenia may be more frequent in rheumatoid arthritis than in inflammatory bowel disease. ${ }^{2}$

In this study we report our experience of the incidence, severity, and outcome of sulphasalazine related leucopenia in rheumatoid arthritis over five years. Possible predictive factors have been examined.

\section{Patients and methods}

Over the past six years 252 patients with rheumatoid arthritis have received sulphasalazine during prospective studies. Others have been treated with sulphasalazine without being enrolled in a formal study (number unknown). The policy in our unit is to monitor full blood count fortnightly for the first 12 weeks, then six weekly until one year, then three monthly thereafter, unless particular problems arise. This was carried out either wholly at the rheum-

Accepted for publication 17 October 1988.

Correspondence to $\mathrm{Dr} \mathrm{H}$ A Capell, Centre for Rheumatic Diseases, Royal Infirmary, Glasgow G4 OSF. atology clinic or partly by the general practitioner with telephone contact with the clinic as required.

The case notes of 20 patients who were known to have developed leucopenia (white blood cell count $\left.<4 \times 10^{9} / 1\right)$ during sulphasalazine treatment were reviewed. The following information was sought: sulphasalazine dose, length of treatment, initial white cell count on starting sulphasalazine treatment, lowest white cell count, recovery time, previous or subsequent leucopenia and its relation to gold or penicillamine treatment. Additional information collected included platelet count, bone marrow findings, rheumatoid factor titre, antinuclear antibodies, and HLA-DR phenotype when available.

\section{Results}

Of the 20 patients (18 female, two male), 14 were participating in prospective studies of sulphasalazine efficacy and six had received sulphasalazine outwith a formal study. The total prospective cohort comprised 252 patients. The incidence of leucopenia in this group was $5.6 \%$. The complete case notes of one of these patients were not available. Median age at the time of leucopenia was 51 years (range $30-69$ ), median duration of disease was seven years (range 1-35). The minimum duration of follow up in all 20 patients was one year. Leucopenia led to discontinuation of sulphasalazine in 10 patients. Of these, six were patients included in studies of 


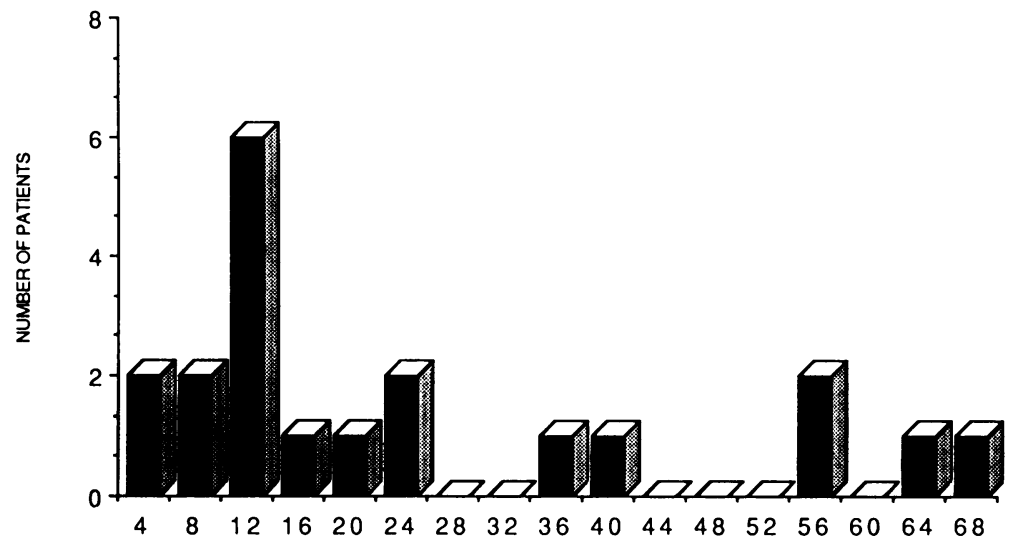

Fig. 1 Number of patients ( $\mathbf{\square}$ developing leucopenia during sulphasalazine treatment.

WEEKS ON TREATMENT

Table 1 Haematological details. Values show median (range)

\begin{tabular}{lccc}
\hline & $\begin{array}{l}\text { Early } \\
\text { (before 24 weeks) } \\
(n=14)\end{array}$ & $\begin{array}{l}\text { Late } \\
\text { (after 24 weeks) } \\
(n=6)\end{array}$ & $\begin{array}{l}\text { Total } \\
(n=20)\end{array}$ \\
\hline Time to fall in WBC $^{*}$ (weeks) & $9(2-21)$ & $61(36-68)$ & 10 \\
WBC $\times 10^{-9} / 1$ (before sulphasalazine) & $5 \cdot 4(3 \cdot 4-12.4)$ & $6 \cdot 1(4 \cdot 4-7 \cdot 7)$ & $5 \cdot 9(3 \cdot 4-12 \cdot 4)$ \\
WBC $\times 10^{-9} / 1$ (minimum) & $3 \cdot 0(0 \cdot 5-3 \cdot 8)$ & $3 \cdot 4(2 \cdot 8-3 \cdot 7)$ & $3 \cdot 3(0 \cdot 5-3 \cdot 8)$ \\
Platelets $\times 10^{-9} / 1$ (before sulphasalzine) & $322(113-664)$ & $422(289-617)$ & $350(113-664)$ \\
Platelets $\times 10^{-9} / 1$ (minimum) & $245(84-859)$ & $307(253-462)$ & $266(84-859)$ \\
Recovery time (weeks) & $1(0 \cdot 7-3)$ & $3(1-6)$ & $2(0 \cdot 7-6)$ \\
\hline${ }^{*}$ WBC $=$ white blood cell count. & & & 0
\end{tabular}

sulphasalazine efficacy-that is, $2 \%$ of the prospective group, and four were patients not in the studies.

The median duration of treatment before leucopenia in all patients was 10 weeks (range 2-64) (Fig. 1). The patients were divided into two groups based on the average duration of treatment before the development of leucopenia-that is, early (before 24 weeks), and late (after 24 weeks). Lymphopenia occurred in all patients, but $13 / 20$ $(65 \%)$ were also neutropenic. There was no difference between the two groups either in the occurrence of neutropenia or in any of the measured variables (Table 1).

Bone marrow aspirates had been performed in seven patients, of whom two showed failure of granulopoiesis and five showed no abnormality. The absence or presence of splenomegaly at the time of leucopenia had been noted in 16 patients, of whom seven had an enlarged spleen.

Sixteen of $20(80 \%)$ of patients were seropositive for rheumatoid factor and 10 out of $15(67 \%)$ were antinuclear antibody positive. HLA-DR typing in 13 patients showed $2 / 13(15 \%)$ to be DR3 positive and $9 / 13(69 \%)$ to be DR4 positive.
Treatment was discontinued in 10 patients owing to severity of leucopenia, lack of efficacy, or patient unwillingness to continue treatment. Infective $\bar{\alpha}$ complications arose in only two of the neutropenic patients. $^{2}$ The remaining 10 patients continued to receive an adjusted sulphasalazine dose to maintain $\widehat{\varrho}$ a white cell count above $3.5 \times 10^{9} / 1$ and a neutrophil count above $2 \cdot 0 \times 10^{9} / 1$. Gold and penicillamine had음 been prescribed in 17 patients either before or after $D$ sulphasalazine treatment; four of these patients developed leucopenia.

\section{Discussion}

Leucopenia occurred in $5.6 \%$ of patients with rheumatoid arthritis treated prospectively with sulphasalazine. The incidence of sulphasalazine $\frac{\bar{\Phi}}{\mathbb{D}}$ related leucopenia was higher in this cohort than $\stackrel{\oplus}{+}$ other rates previously reported. In a study from 0 three centres Glasgow was found to have a leuco- $\bar{O}$ penia rate higher than that of Birmingham or Sheffield. ${ }^{2}$ The seven patients included in that report are the first seven of our series of $20 . \bar{\sigma}$ Subsequent to the publication of that paper, however, 
other workers from Birmingham found neutropenia in $1.6 \%$ of their patients, three of them severe, and a further $3 \%$ developed leucopenia during their treatment. ${ }^{3}$ Follow up in those patients was over 18 months. In a multicentre study from the United States Williams et al found leucopenia in two of their 69 patients treated with sulphasalazine and followed up for 37 weeks. $^{4}$

It may be important to differentiate isolated lymphopenia from leucopenia. Lymphopenia may arise owing to differences in the metabolism of sulphasalazine in rheumatoid arthritis or, alternatively, disease factors such as hypersplenism may be contributory. Interestingly, sulphasalazine is also known to result in generalised lymphadenopathy, ${ }^{5}$ but it is not known to cause splenomegaly and is not directly lymphocytotoxic. ${ }^{6}$

Discontinuation of treatment was necessary in half of the patients reviewed in the present study. Although most episodes of leucopenia occurred early, $6 / 20(30 \%)$ developed after 24 weeks of treatment. In view of this it is suggested that the white cell count should be monitored for the duration of sulphasalazine treatment.

Sulphasalazine was continued in a reduced dose in 10 patients once the leucopenia had recovered. Three of these patients had both a lymphopenia and a neutropenia and the remainder were only lymphopenic. In only one patient was the drug discontinued because of further toxicity; this patient developed a neutropenia on reintroduction of the drug. Our current policy is to withdraw sulphasalazine if the total white cell count falls below $4 \times 10^{9} / 1$ and reintroduce it at a lower dose once the white cell count has recovered, with more frequent monitoring of the total and differential white cell counts. We do not, however, continue sulphasalazine treatment in patients with a significant neutropenia.

Although recovery of the white cell count on withdrawal of sulphasalazine was rapid, fatal cases have been reported. ${ }^{7}$ There is thus a need for continued vigilance if this useful second line drug in rheumatoid arthritis is to be used with optimum benefit.

We should like to thank Mrs A Thomson for assistance in collection of these data and Miss A Tierney for typing the manuscript.

\section{References}

1 Capell H A, Pullar T, Hunter J A. Comparison of white blood cell dyscrasias during sulphasalazine therapy of rheumatoid arthritis and inflammatory bowel disease. Drugs 1986; 32 (suppl 1): 44-8.

2 Amos R S, Pullar T, Bax D E, Situnayake D, Capell H A, McConkey B. Sulphasalazine for rheumatoid arthritis: toxicity in 744 patients monitored for one to 11 years. $\mathrm{Br} \mathrm{Med} \mathrm{J} \mathrm{1986;}$ 293: 420-3.

3 Farr M, Tunn E J, Symmons D P M, et al. Sulphasalazine in arthritis: haematological problems associated with therapy. $\mathrm{Br} J$ Rheumatol 1986; (suppl): Abstr 36.

4 Williams H J, Ward J R, Dahl S L, et al. A controlled trial comparing sulphasalazine, sodium gold thiomalate, and placebo in rheumatoid arthritis. Arthritis Rheum 1988; 31: 702-13.

5 Carr P, Lock D L, Ali M. Glandular fever like illness associated with sulphasalazine. Postgrad Med J 1982; 58: 665-6.

6 Ali A T, Barsan G S, Morley J. Mode of action of sulphasalazine: an alternative view. Lancet 1982 ; i: $506-7$.

7 Danielson D A, Douglas S W, Herzog P, Jick H, Porter J B. Drug induced blood disorders. JAMA 1984; 252: 3257-60. 